$\mathrm{T}$ he first thing I do when I get up is brush my teeth. The time I get up depends on what shift I'm doing; if it's 8 am to $2 \mathrm{pm}$, I set my alarm for 6.20 am, snooze for 30 minutes, get up at $6.50 \mathrm{am}$ and am in my car at 7 am. I shower the night before!

I don't usually eat breakfast, which I know is naughty, but I do have a strong black coffee with sweetener when I get to work. Recently I have been trying to have at least a banana in the morning.

I live about 30 miles from work - roughly a 45-minute drive depending on the time of day. My wife Amy and I recently moved to Bushey, Hertfordshire. I grew up in Edgware, NW London, and after graduating from Birmingham, moved to Uxbridge for my first associate job.

I normally drive alone, occasionally dropping my wife off at the train station. I listen to Talk Radio but if this is too depressing, then some music. It's an excellent time for reflection.

On average I see patients 36 hours a week. A break or, dare I say, a failed-to-attend patient, can be a welcome relief. Mondays and Tuesdays I'm at Windsor Road Dental Practice in Slough; I work 8-2 and 2-8 on alternate weeks; however, I will usually go in earlier or stay behind later for DF1 commitments. I work at Cookham Dental Practice Wednesday and Friday 8-2 or 2-8 - again alternating weekly - Thursday 8-8 and one Saturday a month from 9 am to $1 \mathrm{pm}$.

On an average day, assuming an early start, I arrive at the practice by around $7.45 \mathrm{am}$, change into my tunic, load up the computer and check what my day is like. Once happy that there aren't too many root canals booked in, I will drink my strong black coffee. Once I've had my first sip, I'm prepared to take on the day. This normally involves a series of check-ups and routine dentistry with maybe the odd walk-in emergency or broken tooth thrown in for good measure. Occasionally

\section{ALWAYS TRY TO SEE THE GOOD IN A SITUATION}

Dentist Jonathan Lightstone, 30, qualified from Birmingham Dental Hospital in 2006 and works at Cookham Dental Practice and Windsor Road Dental Practice, both part of Rodericks Limited. He has been married to Amy, a project manager for London's medical and healthcare education and training, for two years.

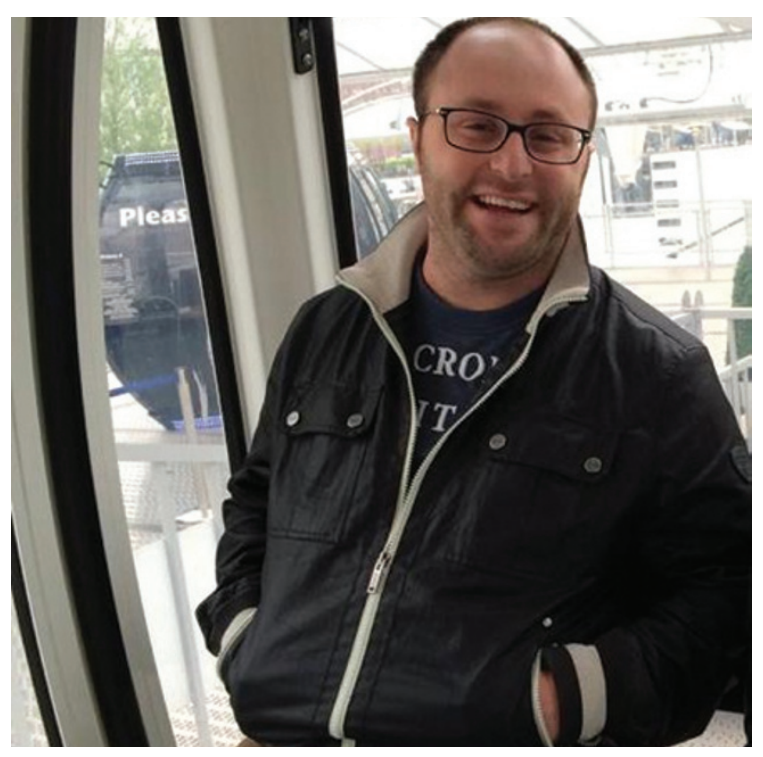

I may be reviewing one of my short term ortho cases. When they have the chance, the receptionists will bring me in a list of messages, which I often dread as I worry that a patient may not be happy with something.

If at Windsor Road, I will often check on the DF1 or be called in for an opinion. I was given the opportunity to become an FD trainer jointly with one of the directors of Rodericks, Carlos Clark, in 2012. Little did I know at the time that this would change my career pathway.

This is now my second year as a trainer. I am still finding my feet, but would like to think that I'm a fair mentor. I always try to see the good in a situation but should perhaps be a bit firmer. As trainers we are encouraged to do the postgraduate certificate in medical and dental education (PGCME). This course isn't compulsory at the moment, but it helps us become better trainers. It is also challenging and makes us view training dentists in a different light. I enjoy the education career pathway very much: especially the social side of meeting dental peers. Cookham Dental Practice has also recently been awarded a training practice status for a new dental core training pilot (previously DF2) based in general practice. I will be the educational supervisor working along two clinical supervisors in oral surgery and prosthodontics.
This is very exciting for me as well as all the team at Cookham. However, being a pilot, there are some unknowns and 'what ifs' but assuming it works could be fantastic for the practice. I will still be doing this alongside DF1 training.

If I get a gap during my working day I will spend some time catching up with the practice manager - Aaron at Cookham and Amiee at Windsor Road - to see how we are doing in terms of our contractual obligations. Once I am satisfied that everything is up to date, I will eventually go home, or have lunch at $1 \mathrm{pm}$ if doing an 8-8 at Cookham.

It is difficult to have a routine for activities outside work. I'm not getting any younger and my diet isn't getting any better. I try to get to the gym; as a newly-registered member, it is taking time to gather momentum.

Most days I find myself getting home around $8.30 \mathrm{pm}$. Late shifts make it tempting to get a takeout for dinner. While I'm partial to a KFC, I do try to cook more, but I'm not very adventurous. I don't particularly have a sweet tooth, but my wife does (don't tell her I said that), and I may be tempted if she's having something sweet. We like to relax in front of the TV or occasionally pop to the local pub.

I go to bed too late. It's certainly difficult to balance a healthy work life around extended opening hours, or should I say trying to keep or get in shape, as long days do tire you out. I do aspire to owning my own dental practice one day (who doesn't?), but I like the fact that the management team at Rodericks Ltd take care of all the administrative side of dentistry. The amount of work behind the scenes makes you wonder how any dentist can balance their clinical time with all the admin, let alone a life outside of dentistry. I would also like to develop my cosmetic and restorative skills in the future, but at the moment I am enjoying exploring the educational side of dentistry.

INTERVIEW BY KATE QUINLAN 